\title{
Prospective study of the prescribing pattern of antibiotics and their outcome in patients admitted to intensive care unit at tertiary center
}

\author{
Pavithra H. G. ${ }^{1 *}$, Syed Mohsin Ahmed ${ }^{1}$, Krishnamurthy H. A. ${ }^{2}$
}

${ }^{1}$ Department of Pharmacology, ${ }^{2}$ Department of Medicine, Mysore Medical College and Research Institute, Mysore, Karnataka, India

Received: 05 February 2020

Revised: 09 March 2020

Accepted: 11 March 2020

\section{*Correspondence:}

Dr. Pavithra H. G.,

Email: drpavithra1988@gmail.com

Copyright: (C) the author(s), publisher and licensee Medip Academy. This is an open-access article distributed under the terms of the Creative Commons Attribution Non-Commercial License, which permits unrestricted non-commercial use, distribution, and reproduction in any medium, provided the original work is properly cited.

\begin{abstract}
Background: Antibiotics are currently the most commonly prescribed drugs in hospitals, worldwide. overuse of antibiotics has important economic implications. Periodic evaluation of drug utilization in the intensive care unit (ICU) is necessary for optimization of health care system, proper use of resources and making prescription policy because ICU is considered as the epi-center of antimicrobial resistance. The aim of this study is to evaluate antibiotic prescription and consumption patterns at admission into intensive care unit and to know the average costs of antibiotics.

Methods: The prescription data on 250 consecutive patients at admission into the ICU was audited from January to March 2019. Total antibiotics, dose, route and cost of antibiotics were noted and the defined daily dose/100 bed days of most common antibiotics were calculated. Statistical analysis is done using SPSS software.

Results: A total of 689 antibiotics were prescribed in the 250 patients studied that is, an average of 2.28 antibiotics/prescription. Empirical antibiotics were prescribed to all the patients admitted to ICU. Average cost of the antibiotics was rupees 163.89 per patients. The most commonly prescribed antibiotic at ICU admission was ceftriaxone $(62 \%)$ of all prescription. Second most common is metronidazole (32\%). In this study, 76 patients recovered while 174 patients expired.

Conclusions: Our study reveals that antibiotics are widely prescribed in critically ill patients and form significant drug consumed in the ICU. At admission elderly patients are prescribed $>2$ antibiotics and prescribing antibiotics where the cost of antibiotic is high.
\end{abstract}

Keywords: Antibiotics, Prescription, Ceftriaxone, Define daily dose

\section{INTRODUCTION}

Antibiotics are currently the most commonly prescribed drugs in hospitals, worldwide. ${ }^{1}$ In a developing country like India, the cost of health care is a key cause for concern. Many studies have implicated that the antibiotics are among the major group of drugs, which cause adverse drug reactions (ADRs). ${ }^{2}$
Antimicrobial drugs are unique in the sense that their administration may promote colonization of patients and the environment with resistant bacterial strains and so compromise the usefulness of these agents. Besides this serious consequence, the overuse of antibiotics has important economic implications. We decided to monitor antibiotic consumption in relation to indications for therapy in order to identify areas of irrational use and so attempt to improve prescribing patterns. ${ }^{3}$ 
Programs designed to encourage appropriate antibiotic prescriptions in health institutions are an important element in quality of care, infection control and cost containment. $^{4-7}$ Several studies have reported concern about the continuous indiscriminate and excessive use of antimicrobial agents that promote the emergence of antibiotic-resistant organisms. The ICARE study established the high incidence of antibiotic resistance in an intensive care unit in comparison to the community. ${ }^{8}$

Drug utilization has been defined as "the prescribing, dispensing and ingesting of drugs". ${ }^{9}$ Due to availability of limited funds in developing countries, drugs should be prescribed rationally so that the available funds can be utilized optimally. ${ }^{10}$ The intensive care unit (ICU) is considered as the epicenter of antimicrobial resistance and it is an important problem influencing patient outcomes. $^{11}$

Periodic evaluation of drug utilization in the ICU is necessary for optimization of health care system, proper use of resources and making prescription policy. ${ }^{12}$

Defined daily dose (DDD)/100 bed days provide a rough estimate of drug consumption in hospital inpatients and it is a fixed unit of measurement independent of formulation and price. ${ }^{13}$

In the present study, we have evaluated the drug utilization pattern and calculated the DDD for the drugs used in ICU of a tertiary care hospital.

\section{METHODS}

A prospective observational study was carried out, after the permission from institutional review board, government medical college, Mysore, Karnataka. Inpatient case papers of the patients admitted in ICU from January to March 2019 were collected from Mysore medical college, Mysore, Karnataka. The prescription data on 250 consecutive patients at admission into the ICU was audited.

Baseline demographic variables on all patients, such as name, age, gender, hospital number, clinical diagnosis, were recorded. Other variables, such as duration of ICU admission, the total number of drugs prescribed on the day of admission, and the total number of antibiotics prescribed were also noted. Additional data included the generic name, dose, duration, and route of administration of the antibiotic.

All drugs listed on the first prescription slip at admission to the ICU, namely, antibiotics, aerosolized medications, agents used for stress ulcer prophylaxis and deep vein thrombosis, antihypertensives, anticonvulsants, and so on, were noted. Intravenous fluids, drugs given as infusions, such as vasoactive agents, sedatives and insulin, were not included in the analysis. The cost of antibiotics and total drugs prescribed on each patient was calculated.

The antibiotics were classified using the anatomical therapeutic chemical (ATC) classification system and drug utilization was measured as DDD/100 bed-days. In the ATC classification.

system, the drugs are divided into different groups according to the organ or system on which they act and their chemical, pharmacological and therapeutic properties.

The DDD per 100 bed-days was calculated by the formula:

DDD/100 bed-days $=$ No. of units administered in a given period $\times 100 / \mathrm{DDD} \times$ number of days $\times$ number of beds $\times$ occupancy index

where,

Occupancy index $=$ Total in-patient service days for a period $\times 100 /$ total in-patient bed count $\times$ number of days in the period

The daily antibiotic cost per patient was calculated by the multiplication of the cost per unit and the number of doses that were used in each patient. The unit price of each antibiotic and drug used were obtained from the hospital pharmacy.

The study design was observational study. The statistical tests used in this study were descriptive statistics - mean, standard deviation, frequency and percent. The inferential statistics was chi square test.

\section{RESULTS}

A prescription of 250 patients admitted into the ICU were analyzed. This include 165 male and 85 female patients. The average age of the patient was 68 years \pm 7 . Most of our patients are from MICU (61.2\%) and most common diagnosis was COPD (88 patients). The average length of ICU stays 3 days \pm 2 . The demographic data and patient characteristics studied are as given in Table 1. A total of 689 antibiotics were prescribed in the 250 patients studied that is, an average of 2.28 antibiotics/prescription. Empirical antibiotics were prescribed to all the patients admitted to ICU. Average cost of the antibiotics was rupees 163.89 per patients. Figure 1, shows distribution of patients according to the number of antibiotics prescribed (Figure1). Patients admitted in surgical ICU were prescribed the greatest number of antibiotics (Table 2 ). We found that the number of patients who were prescribed 1 antibiotic did not vary from those prescribed $2 /$ more antibiotics with respect to their age, gender, source of admission and total days of ICU stay. However, the number of antibiotics prescribed significantly correlated with poor outcome $(\mathrm{p}=0.000)$. Patients who 
were prescribed more than 2 antibiotics at admission had a significantly age is higher $(\mathrm{p}=0.005)$ and surgical cases had prescribed $>2$ antibiotics and medical cases had prescribed single antibiotic $(\mathrm{p}=0.000)$ (Table 3$)$. The most commonly prescribed antibiotic at ICU admission was ceftriaxone $(62 \%)$ of all prescription. Second most common is metronidazole $(32 \%)$. Table 4 , enlist the 8 most commonly prescribed antibiotics along with their Define daily dose per 100 bed-days (Table 4). The average cost of antibiotics prescribed were significantly lower in older patients ( $>45$ years).

Table 1: Demographic data and patient characteristics.

\begin{tabular}{|lll|}
\hline Variable & Number & $\%$ \\
\hline Gender & \multicolumn{2}{l|}{} \\
\hline Male & 165 & 66 \\
\hline Female & 85 & 34 \\
\hline Age distribution (in years) & \\
\hline $15-30$ & 26 & 10.4 \\
\hline $31-45$ & 63 & 25.2 \\
\hline $46-60$ & 60 & 24 \\
\hline $61-75$ & 87 & 34.8 \\
\hline$>76$ & 14 & 5.6 \\
\hline Department of origin & & \\
\hline Medical & 153 & 61.2 \\
\hline Surgical & 97 & 38.8 \\
\hline Antibiotic prescribed & & \\
\hline 1 & 133 & 53.2 \\
\hline$>1$ & 117 & 46.8 \\
\hline Length of ICU stay & & \\
\hline $0-5$ & 140 & 56.0 \\
\hline $6-10$ & 70 & 28.0 \\
\hline $11-15$ & 22 & 8.8 \\
\hline$>15$ & 18 & 7.2 \\
\hline Outcome & & \\
\hline Discharged & 76 & 30.4 \\
\hline Expired & 174 & 69.6 \\
\hline
\end{tabular}

Total cost of antibiotics was lower in medical patients and statistically significant. Meropenem was the most expensive drug prescribed among our patients Rs.13029. Most of the patients included in this study, 76 patients recovered while 174 patients expired.

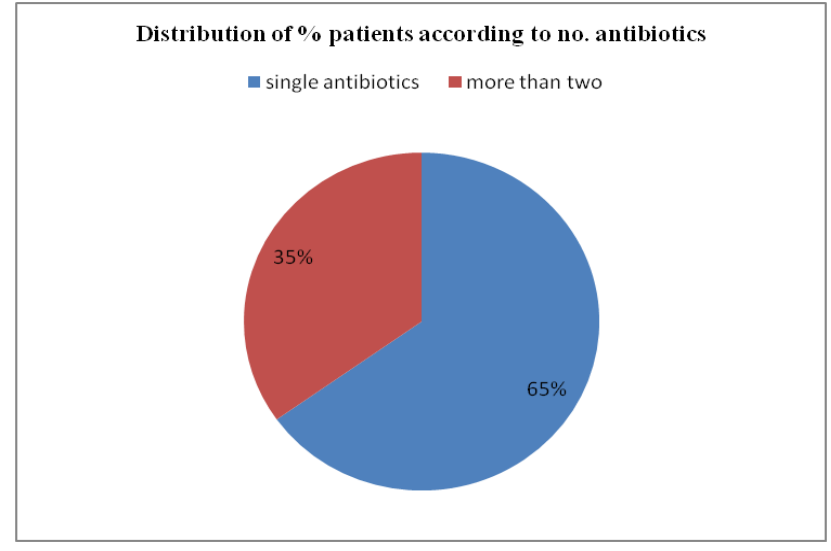

Figure 1: Distribution of (\%) patients according to no. antibiotics.

Table 2: Drug prescription data according to patient diagnosis.

\begin{tabular}{|lll|}
\hline Diagnosis & $\begin{array}{l}\text { Patients } \\
(\mathbf{N})\end{array}$ & $\begin{array}{l}\text { Total antibiotics } \\
\text { (average) }\end{array}$ \\
\hline Surgical & 97 & 212 \\
\hline Trauma/poisoning & 26 & 72 \\
\hline MODS/sepsis & 77 & 122 \\
\hline COPD/pneumonia & 86 & 171 \\
\hline others & 48 & 107 \\
\hline
\end{tabular}

Table 3: Univariate analysis of the factors affecting the number of antibiotics prescribed in patients.

\begin{tabular}{|llll|}
\hline Variables & $\begin{array}{l}\mathbf{1} \text { antibiotics } \\
(\mathbf{n = 1 3 3})\end{array}$ & $\begin{array}{l}>1 \\
\text { antibiotics } \\
(\mathbf{n = 1 1 7})\end{array}$ & $\begin{array}{l}\mathbf{P} \\
\text { value }\end{array}$ \\
\hline $\begin{array}{l}\text { Age } \\
\text { <44/>45 }\end{array}$ & $58 / 75$ & $31 / 86$ & 0.005 \\
\hline $\begin{array}{l}\text { Gender } \\
\text { male/female }\end{array}$ & $89 / 44$ & $76 / 41$ & 0.744 \\
\hline $\begin{array}{l}\text { Diagnosis } \\
\text { medical/surgical }\end{array}$ & $38 / 95$ & $59 / 58$ & 0.000 \\
\hline $\begin{array}{l}\text { Total ICU days } \\
\text { <5/>5 }\end{array}$ & $70 / 63$ & $70 / 47$ & 0.253 \\
\hline
\end{tabular}

Table 4: Most frequently used antibiotics (according to the number of prescriptions).

\begin{tabular}{|llllll|}
\hline Name & ATC code & DDD (gm) & Pre (n) & UNITS & DDD/100 bed days \\
\hline Ceftriaxone & J01DD04 & 2 & 155 & 310 & 2.09 \\
\hline Meropenem & J01DH02 & 2 & 25 & 50 & 0.337 \\
\hline Piptaz & J01CR05 & 14 & 54 & 162 & 0.729 \\
\hline Metronidazole & JO1XD01 & 1.5 & 80 & 240 & 1.08 \\
\hline Linezolid & J01XX08 & 1.2 & 1 & 2 & 0.013 \\
\hline Azithromycin & J01FA10 & 0.3 & 35 & 35 & 0.78 \\
\hline Amikacin & J01GB06 & 1 & 4 & 4 & 0.05 \\
\hline Taxim & J01DD01 & 4 & 6 & 12 & 0.04 \\
\hline
\end{tabular}




\section{DISCUSSION}

Prescriptions of 250 ICU admissions were audited over a 3 months period to study drug utilization patterns in the ICU. The average age of the patient was 68 years \pm 7 and most common diagnosis was COPD (88 patients). The average length of ICU stay was 3 days \pm 2 . In a study on drug use patterns from an ICU in government medical college Gujarat India the mean age of the patient was 44.62 years with average duration of ICU stay was 4.15 days and the most frequent diagnosis at admission was septicemia. $^{14}$ The average number of drugs per prescription is an important index of a prescription audit. It is recommended that the number of drugs per prescription should be kept as low as possible to minimize Our study revealed that Empirical antibiotics were prescribed to all the patients admitted to ICU and a mean of 2.28 antibiotics/prescription were prescribed per patient. Anand et al, Mangalore India $80.4 \%$ patients received one or more AMAs during their ICU admission period. ${ }^{15}$ In our ICU, the most frequently prescribed antibiotic at ICU admission was ceftriaxone $(62 \%)$ of all prescription. Second most common is metronidazole $(32 \%)$. Define daily dose was calculated for 8 antibiotics. Ceftriaxone 2.09 , metronidazole 1.08 , piptaz 0.72 , azithromycin 0.78. In a study at CMC, Ludhiana, the most commonly prescribed antibiotics in ICU were the $3^{\text {rd }}$ generation cephalosporins, levofloxacin, and meropenem. ${ }^{16}$ In our study average cost of the antibiotics was rupees 163.89 per patients. On reviewing other studies from India, we found total AMA cost per patient varied from 4364 to 1995 INR. Meropenem was the most expensive.

The strengths of our study were that it was conducted prospectively, and we studied the interrelation of the number and cost of antibiotics prescribed with various parameters, such as age, diagnosis, gender, LOS, and mortality. To date, there are limited studies on drug utilization and expenditure due to antibiotic usage, especially from Indian adult ICUs. These data are relevant as our health care system is largely based on individual paying capacity with limited insurance or government funding to critically ill patients. Hence, data on drug costs, especially antibiotic costs are particularly useful in formulating policies on health care systems and expenditure in India.

The limitations of our study were that only the drug prescriptions at admission were audited, and hence this may not reflect drug usage patterns as a whole in the ICU. Also, the subsequent reduction or escalation of antibiotics, which were started empirically could not be studied. The utilization of intravenous fluids, vasoactive drugs, sedatives, insulin, and equipment's used, such as tubes, catheters, and so on, was not studied. Siddiqui et al, reporting from a developing country, found that creation of a restriction program using an infectious disease specialist helped reduce the antibiotic prescriptions of broad spectrum antibiotics by $34 \% .{ }^{17}$
Use of antibiotic rotation policies in the ICU, regular audits, and feedback reviews are also useful tools to check the use of irrational antibiotic therapy in the ICUs. Education of the prescriber is the cornerstone of any successful antibiotic stewardship program and teaching of guidelines and clinical pathways will aid in improving antimicrobial prescribing behavior to a large extent.

\section{CONCLUSION}

Our study reveals that antibiotics are widely prescribed in critically ill patients and form significant drug consumed in the ICU. At admission elderly patients are prescribed $>2$ antibiotics and prescribing antibiotics where the cost of antibiotic is high.

\section{ACKNOWLEDGEMENTS}

We thank Mr. Lancy D. souza for statistical analysis.

Funding: No funding sources

Conflict of interest: None declared

Ethical approval: The study was approved by the Institutional Ethics Committee

\section{REFERENCES}

1. Faryna A, Gilbert L. Wergowske, Kim Goldenberg. Impact of therapeutic guidelines on antibiotic use by residents in primary care clinics. J Gen Intern Med. 1987;2:102-7.

2. Padmaja U, Adhikari P, Pereira P. A Prospective Analysis of Adverse Drug reactions in a South Indian hospital. Online J Health Allied Sci. 2009;8:12.

3. Reder BL, Nielsen SL, Magnussen P, Engquist A, Frimodt MUN. Departments of "Clinical Microbiology and Anaesthesiology and Intensive Care, Bispebjerg Hospital, University of Copenhagen, Denmark.

4. Goldman DA, Weinstein RA, Wenzel RP. Strategies to prevent and control the emergence of antimicrobial resistant micro-organisms in hospital. JAMA. 1996;275:234-49.

5. Stevenson RC, Blackman SC, Williams CL, Bartzokas CA. Measuring the saving attributable to an antibiotic prescriptionpolicy. J Hosp Infect. 1988; 11:16-25.

6. Lesar TS, Briceland LL. Survey of antibiotic control policies in university-affiliated teaching institutions. Ann Pharmacother. 1996;30:31-4.

7. Strum W. Effects of a restrictive antibiotics policy on clinical efficacy of antibiotics and susceptibility patterns of organisms. Eur J Microbiol Infect Dis. 1990;9:381-9.

8. Lemmen SW, Hafner H. Influence of an infectious disease service on antibiotic prescription behavior and selection of multiresistant pathogens. Infection. 2000;28:384:7.

9. Lunde PKM, Andrew M, Baksaas I. Drug Utilization - an instrument in drug research. In Epidemiological 
concepts in clinical pharmacology. Kewitz H, Roots I, and Voight K (eds). Springer-Verlag: Berlin; 1987: 57-63.

10. Shankar PR, Partha P, Dubey AK, Mishra P, Deshpande VY. Intensive care unit drug utilization in a teaching hospital in Nepal. Kathmandu Univ Med J (KUMJ). 2005;3:130-7.

11. Curcio DJ, On behalf of the Latin American antibiotic use in intensive care unit group. Antibiotic prescription in intensive care units in Latin America. Rev Argent Microbiol. 2011;43:203-11.

12. WHO Collaborating Centre for Drug Statistics Methodology. Guidelines for ATC Classification and DDD Assignment. Oslo: WHO Collaborating Centre for Drug Statistics Methodology; 2002.

13. WHO Collaborating Centre for Drug Statistics Methodology. ATC Index with DDDs. Oslo: WHO Collaborating Centre for Drug Statistics Methodology; 2002.

14. Patel MK, Barvaliya MJ, Patel TK, Tripathi CB. Drug utilization pattern in critical care unit in a tertiary care teaching hospital in India. International journal of critical illness and injury science. 2013;3(4):250.

15. Anand N, Nayak IN, Advaitha MV, Thaikattil NJ, Kantanavar KA, Anand S. Antimicrobial agents' utilization and cost pattern in an Intensive Care Unit of a Teaching Hospital in South India. Indian J Critical Care Med. 2016;20(5):274.

16. Williams A, Mathai AS, Phillips AS. Antibiotic prescription patterns at admission into a tertiary level intensive care unit in Northern India. J Pharm Bioallied Sci. 2011;3(4):531.

17. Siddiqui S, Hussein K, Manasia R, Samad A, Salahuddin N, Zafar A, et al. Impact of antibiotic restriction on broad spectrum antibiotic usage in the ICU of a developing country. J Pak Med Assoc. 2007;57:484-7.

Cite this article as: Pavithra HG, Ahmed SM, Krishnamurthy HA. Prospective study of the prescribing pattern of antibiotics and their outcome in patients admitted to intensive care unit at tertiary center. Int J Basic Clin Pharmacol 2020;9:743-7. 